\title{
Integration of Cultural Teaching into Cultivating College Learners' Communicative Competence
}

\author{
Qian Li \\ Foreign Languages Department of Shandong Jiaotong University, Jinan, China
}

\begin{abstract}
It is a universal consensus that language is a part of a certain culture and the acquisition of a foreign language is also the acquisition of a foreign culture. The study of communicative competence has recieved increasingly more attentions in the field of English teaching and learning, and a great deal has been discovered about the cultural teaching and communicative competence. This dissertation aims at prasenting a brief analysis of how we cultivate college learners' communicative through the way of cultural teaching. Firstly, the theoretical issues on culture and communicative competence are presented. An experimental study is conducted and analyzed in the second part. And pedagogical implications of cultural teaching is made accordingly. The integration of cultural teaching into the practice of English teaching as a foreign language acquisition is proved to be an effective way to cultivate college learners' communicative competence.
\end{abstract}

\section{Index Terms - Integration, Cultural teaching, Communicative competence}

Applied linguists and language teachers are increasingly aware that a foreign language can rarely be acquired or learned without addressing the culture of the community in which it is spoken and used. Linguistic competence is not enough to ensure a successful cross-cultural communication. A widely accepted idea is that cultural teaching must be taken as an essential part to cultivate and develop the college learners' ability for communicating.

\section{Theoretical IsSues on CULture ANd COMmunicative COMPETENCE}

A. Culture

In 1957, Robert Lado submed cultural teaching under foreign lanugage teaching (Lado, 1957). Since then numerous works and papers focused on cultural teaching have been released at home and abroad. Hall (2005) claimed that the notion of culture had always been considered an important concept in applied linguistics.

There are almost 200 definitions of culture in numerous ways. However it is defined, culture influences how we adapt and learn language, it also shapes people's thinking, acting and communicating according to group expectations.

There would have been a great deal of agreement concerning the major characteristics of culture regardless of many definitions we could have examined. The characteristics of culture can be summerized as the following: culture is a learned but not inherited behavior through communication; culture is shared by a group but not an isolated person; culture is symbolized with language as the most important symbolic system; culture is a unity and culture is never static.

Language does not exist in a vacuum. The relationship between language and culture cannot be ignored since culture is a set of values and beliefs which are prevalent within a given society or section of a society. If communication is assumed as swimming, then language is the swimming skill, and culture is water. Without language, communication would remain to a very limited degree in very shallow water; without culture there would be no communication at all. The relationship between language and culture can be supposed as the following

From a communication view:

$\begin{array}{lcc}\text { Language } & \text { culture } \rightarrow \text { communication } \\ \text { swimming skill } & \text { water } & \text { swimming }\end{array}$

On the basis of the above theory, language and culture cannot be seperated from each other.

\section{B. Communicative Competence}

Communicative competence is a complicated concept and has been put greater emphasis on in the foreign language teaching practice. Many definitions exit in the second language acquisition academy with the aim to reveal the nature and law of the language. The study and exploration of a second language is different from that of the mother-tongue which is of a more natural process. It can not be denied that the ultimate goal of the foreign language teaching is to cultivate the communicative competence of the learners. Bearing the purpose in mind, learners will have to posses a sort of competence, with which they might be able to use language appropriately and effectively. And this kind of competence is known as communicative competence.

Communicative competence is an extremely complex system of knowledge and ability, which includes a person's language knowledge, social background knowledge, literature knowledge, cognitive competence, emotional elements, 
and so on. Just as Kramsch pointed out, language was the guide to social reality (Kramsch, 2000). Therefore, the task and goal of foreign language teaching can not be limited to passing on linguistic knowledge.

\section{Culture and Communicative Competence}

During the process of cross-cultural communication, ignorance of cultural aspects is a major factor hindering achieving successful communication. Therefore, foreign language teaching should lay special emphasis on cultural teaching with the aim of cultivating college learners' communicative competence.

The aims of cultural teaching are as to help students to develop an understanding of the fact that all people exhibit culturally-conditioned behaviors and to help students become more aware of conventional behavior in common situations in the target culture. Cultural teaching is also expected to help students increase their awareness of the cultural connotations of the words and phrases in the target culture and then stimulate students' intellectual curiosity about target culture and eventurally help students develop the necessary skills to locate and organize information about the target culture and so on.

The aims of cultural teaching should be combined with the practical teaching situation in the teaching of culture course to reach more comprehensive cultural aims, that is, increasing learners' cultural awareness and cultivating their communicative competence. To be exact, the college learners of English as a foreign language must bear the following aims of cultural teaching and learning in mind. First of all, the cultural teaching is to help the learners to develop an understanding of the fact that all people exhibit culturally-conditioned behaviors. Next, it is to help the learners to increase their awareness of the cultural connotation of the words and phrases in the target culture. Also, the cultural teaching is to help the learners to develop the necessary skills to locate and organize the information on the target culture.

Brown (2002) argued that there are some teaching principles the instructors must attach great importance to in the teaching practice. Teachers should follow the following cultural teaching principles for the development of students' preliminary culture awareness in the teaching activities. First of all, target language should be used as the primary vehicle to teach culture. Secondly, negative effects of native culture on target culture teaching should be prevented. Also important is cultural comparison method should be employed in the process of cultural teaching.

The main purpose of cultural teaching which aims at enhancing the learners' communicative competence is to produce certain language forms in an acceptable way. Dodd claimed that "Intercultural effectiveness is the goal of intercultural communication" (Dodd, 2006, p.26). The teacher's overall purpose is to prepare the students with the necessary linguistic forms and the necessary links between forms and meanings. The teachers should also help the learners to gain insight into general concepts of culture and acquire the ability of critical thinking and action regarding the target culture.

In consideration of the principles and purpose of cultural teaching mentioned above, the selection of the contents of cultural teaching is of great importance. The following contents should be taken into consideration. Cultural connotation of words, expressions and idoms with distinct target culture features, cultural factors that interfere with verbal ommunications and nonverbal communications, knowledge of politics, economics, history and contemporary social situation of the English-speaking countries, differences of cultural values and thinking patterns and their influence on the communication patterns and so on.

\section{An EXPerimental Study of Cultivating LeARners' Communicative Competence through Cultural} TEACHING

\section{A. Objective of the Experiment}

Despite the well known fact that cultivating college learners' communicative competence is one of the main tasks we face in the foreign language teaching, little attention is paid to doing this. The study of English not only includes developing language skills but also understanding the significance of behaviors, values and other cultural background of the English-speaking countries. Because language is inseperable from culture, the acquisition of a foreign language is also the acquisition of a foreign culture. Therefore, the purpose of the experiment is to see whether college learners' communicative competence can be developed through culture teaching.

\section{B. The Subjects}

Due to the situational limitations, it was difficult to choose the subjects by means of random sampling, so I adopted a convenience sampling instead. Convenience sampling, as the name suggests, means that elements are selected as the sample for the convenience of the researcher. So I chose 97 students of my own classes as the subjects for the experiment.

The subjects are 97 sophomore students in Shandong Jiaotong University. The students are all Chinese, aged from 18 to 20. They entered this university in 2011 and they are from all over China. They are undergraduate students and most of them have studied English for about eight years. They are non-English majors and science department students. One class is from the Automobile Engineering Department and it is treated as the Experimental Class (E-C). Another one is from the Mechanical Engineering Department and it is regarded as the Controll Class (C-C). During the teaching process, cultural teaching is adopted consciously in the $\mathrm{E}-\mathrm{C}$ and unconsciously in the $\mathrm{C}-\mathrm{C}$. 
The subjects from these two classes have common entry assessment and curriculum approaches. All of them have learnt English for about 8 years in junior and senior high schools and for one year at college. The sizes of these two classes are 48 and 49 students respectively. The subjects are of intermediate level in English. In other words, they are non-English majors with limited proficiency in understanding and speaking English who need intensive instruction in English.

In this study, all of the subjects in my classes responded to the questionnaire, which was used as a supplementary research tool in this study. As a result, 97 students' data were adopted for statistical analysis.

\section{Instruments and the Designs}

Based on the related theories, the present study attempts to verify the feasibility and effectiveness of cultivating learners' communicative competence through cultural learning and teaching. Therefore, data will be collected to explain the phenomenon from tests and the questionnaires. In order to be congruous with the research purposes, the instruments used in the present study are pre-survey questionnaire, pretest, post-test and post-survey questionnaire.

\section{Procedure}

In the first semester of 2011 to 2012 academic year, the experiment was carried out, which was divided into six stages and finished in 18 weeks. (See Table 2.1)

TABLE 2.1

TIME ALLOCATION OF THE EXPERIMENT

\begin{tabular}{|l|l|}
\hline Week & Content \\
\hline Week 1 & Pretest \& pre-survey questionnaire \\
\hline Week 2-6 & Culture-loaded words and idioms \\
\hline Week $7-11$ & Verbal communication and non-verbal communication \\
\hline Week 12-16 & Difference of cultural values and thinking patterns \\
\hline Week 17 & Post-test \& post-survey questionnaire \\
\hline Week 18 & Summary \\
\hline
\end{tabular}

The first stage is carried out at the very beginning of the experiment. A pretest and pre-survey questionair are conducted with the aim of making sure that the two classes are in the same ground. Thus, the releability and authority of the experiment can be assured. Another important reason for doing this is that we can find out the main factors hinding the college learners' communicative competence and what are the effective measures we can adopt in the following stages of the experiment to develop and enhance college learners' communicative competence.

At the second stage, culture-loaded words and idoms are taught in the experiment. With the development of foreign language teaching, cultural factors have been paid an increasing attention to vocabulary teaching. Deng Yanchang and Liu Runqing stated that the learning of a foreign language is more than merely mastering the pronunciation and grammer but also the behavior of the society. (Deng Yanchang \& Liu Runqing 1989). Suitable use of the words is inseperable from the precise understanding of its cultural background information. Therefore, the direct motive to teach culture in vocabulary is to enable students to use words and experissions appropriately in particular context. A typical example illustrates the importance of the learning of the cultural loaded words. In the textbook, New Horizon College English, book 1, there is a passage entitled "The Trashman". Two words are listed as new words in the word bank, they are "trashman" and "garbageman". It seems like these are two simple words and don't belong to the core vocabulary. But the fact is that these are two important words with deep cultural meaning. "Garbageman"or "trashman"can also be addressed as "environmental engineers" or "sanitation engineers" and this kind of phenomenon is known as euphemism. The college learners are aroused great curiosity of the learning of euphesism. They are encouraged to find more examples. "shoemaker" is called "shoe rebuilder" and "dishwasher" is called "utensil maintenance man" and so on. The following sentence is my favorite to be used as an example and the learners will definitely momorize the importance of learning the cultural knowledge when studying language. It is an advertising slogan and expressed as "Shoes for street walkers, come in and have a fit". It seems that there is nothing wrong with the sentence. In fact, there is a serious mistake in it. "street walkers" does not refer to the people who walk on the street but the prostitute instead. The cultural meaning which is attached to the euphemism cannot be ignored in the study of a foreign language.

The study of verbal communication and non-verbal communication is the main task of the third stage. It cannot be denied that both verbal and non-verbal communication can be quite different in the target culture and the native culture. Therefore, students are encouraged to explore the simmiraties and defferences of both verbal and non-verbal communication between native culture and foreign culture in this stage. For example, the concept of time and space is quite different among the people who come from the west and the east. Being unable to understand the difference between people's concept of time and space is one of the major barriers to the failure of cross-cultural communication. A series of activities are designed and conducted for the purpose of helping the learners understand the importance of non-verbal communication in practice.

The forth stage focuses on the learning of differences of cultural values and thinking patterns. As is known to all, cultural differences not only refer to the superficial differences such as the language, dressing and food etc, but also the invisible differences existing in the deep structure of a culture which includes the values, ideas, and thinking patterns. In this stage, students are helped to extend their vision and expand their mind while understanding the target culture. Also, 
it is important to adapt to the thinking patterns of the target culture with the aim of communicating appropriately with the target culture. One of the most common barriers to the foreigners in the cross-cultural communication is the different thinking patterns which will directly lead to the different organizations of discourse. According to Tao Jiawei, western people prefer to express their ideas directly and openly whereas eastern people like curved mode of thinking. (Tao Jiawei, 1998). Besides, western people like thinking explicitly and eastern people prefer thinking implicitly. Culturally-oriented thinking mode has a direct and profound influence on the improvement of the learners' writing skill. To lick this problem, the analysis of the structure of the discourse is taught at this stage since grasp of grammatical rules is far from enough to guarantee a successful communication.

The post-test and post-survey questionnaire is conducted at the fifth stage. The post-test is used to examine the changes of E-C and C-C after the experiment which is significant to the success of the experiment. The post-survey questionnaire was to examine the sample students' attitude and reaction to this experiment which can be used as an instrument to measure whether this experiment is successful or not.

At the sixth stage, a summary of the experiment is made.

\section{E. Results and Discussions of the Experiment}

Data are collected and analyzed after the experiment. The results and discussions of the experiment are as the following:

According to the pre-survey, the major elements hindering college learners' development of communicative competence are the relatively weak cultural awareness, motivations of learners and the negative effects of the CET-4 and etc.

As to motivations, 18(37.5\%) students from the E-C class and 19(38.8\%) students from the C-C class choose "English is useful" as their answer; $8(16.7 \%)$ students from the E-C class and $9(38.8 \%)$ students from the C-C class choose "to follow the fashion"; 21(43.6\%) from the E-C class and 24(48.9\%) students from the C-C class choose "for a good job"; 16(33.3\%) students from the C-C class and 14(28.6\%)students from the E-C class choose "to be a postgraduate"; $38(79.2 \%)$ students from the E-C class and $42(85.7 \%)$ students from the C-C class choose "English is required by school and I have to pass CET-4"; 18(37.5\%) from the E-C class and 17(34.7\%) students from the C-C class choose "I like English and I want to learn more about the World" as their answer.

It is clear that students of different levels have different motivations. Motivations can be quite different among those who are of the same level. The statics above show that the sample students' goals are functional and they lack enthusiasm and interest in the English study.

There are also many effective ways put forward by the sample students such as learning cultural knowledge in combination with the content of textbooks, spending some time on each class to learn the cultural knowledge, obtain the cultural knowledge through learning some idoms and expressions and so on. Teaching activities are the means by which our teaching aims are fulfilled. It is obvious that our teaching activities are more flexible and rich than before and modern teaching methods give priority to teaching and learning practices which aim to develop college learners' cultural awareness. The sample students suggested a variety of teaching activities leading to culture-oriented learning such as enhancing the ability with of help of the films and the study of English idoms, word-guessing games, role-playing controlled through cues and information and so on.

\section{Pedagogical Implications of CUltural TeAChing}

It can not be denied that cultural teaching has been attached increasingly greater importance in the college because learning a new language is inseperable from the learning of its culture. The fact that the college learners' cultural awareness and communicative competence are still relatively weak makes the college educators realize the importance of integrating cultural teaching into the practice of developing students' communicative competence. The experiment conducted above gives us some pedagogical implications.

\section{A. Arouse College Learners' Interest in Cultural Teaching}

As is often stated, interest is the best teacher for learning. Nevertheless, the fact is that the majority of the Chinese college students attach great importance on the study of the linguistic competence but often ignore the examination of the communicative competence because of the constraints of CET-4. Therefore, the first step to implement cultural teaching is to arouse college learners' interest in it. There are many ways to arouse and increase the college learners' interest and curiosity of learning English as a foreign language. Listening to the classic English songs and appreciating the films, especially those which won the Oscar award, do bring a lot of benefits to the students. The teachers are also suppose to help the students to combat the fear the making miatakes in the process of learning. Once the students are brave enough to speak and write in English, their interest in learning English will greatly boost.

\section{B. Cultivate College Learners'Awareness in Cultural Teaching}

Cultural awareness is the term we have used to describe the sensitivity to the impact of culturally induced behaviors on language use and communication. Cultural awareness turns out to be one of the most important steps toward developing students' communicative competence. In the book, Context and Culture in Language Teaching, the author 
Kramsch (1993) stated that developing cultural awareness means being aware of members of another cultural group.

Davis believed that there are four levels of cultural awareness. (Davis, 2001). At the first level, the learners hold superficial stereotypes and they regard the foreign culture as exotic and bizarre things. Cultural conflicts occur at the second level because learner become more familiar with the target culture and differences in values and behaviors are discovered. Significant subtle contrasts are made at this level. At the third level, the learners shift their attitudes toward the culture, progressing from "unbelievable" to "believable". At the forth level, the learners have taken cultural awareness as an inside element. The learners need to achieve at least the third level in order to become effective intercultural communicators.

The result of the experiment concerning cultural teaching indicates that before the experimental study, most students from both the EC and CC have a weak cultural awareness. After the experiment, the students from the EC have a significant increase in their cultural awareness. The experiment of cultural teaching proved to be an effective way to increase the college learners' cultural awareness. For example, in the process of the cultural teaching, students are encouraged to find out the exact meaning of such abbreviations as "DINK", "CEO", "KFC" and so on. Though these abbreviations are often used in our daily life, most students don't know what precisely they stand for. After the experiment of cultural teaching, a majority of the student from the EC pay special attention to the English used in the daily life instinctively. Developing cultural awareness means being aware of the behaviors, expectations and values of another cultural group. It also means the learners of the foreign language attempt to understand the native speakers' reasons for their beliefs and actions. Ultimately, this needs to be converted into skills in communicating across cultures. Therefore, it is necessary for the second and foreign language learners to become learners of the culture which is the context of the language.

\section{Make Cultural Teaching a Conscious and Purposeful Activity}

Traditional English classroom teaching focuses mainly on the development of the linguistic competence. To meet the demands of the society, cultural teaching which aims at improving and enhancing the communicative competence of the college learners should become a conscious and purposeful process. A vatiety of teaching activities, such as presenting models and theories of culture teaching, inviting learners to share their experiences, can be taken during the teaching process. Moran (2004) put forward several guidelines for teaching culture. The guidelines include teachers should be learners of culture, the teachers must play different roles in each stage and so on. By triggering awareness and understanding of the nature, learners can articulate their intentions and identify approprite strategies to advance their culture learning.

A model for cultural learning, which is distinct from others, was put forward by Gochenour and Janeway in 1993. In their opinion, the process of cultural teaching and learning is such an acticity with specific intention. The learners of this kind of activity will have to accomplish a series of tasks in the culture consciously.

\section{CONCLUSION}

Language is one of the most often used tools for communication. The purpose and the most fundamental task of language teaching is to cultivate the college learners' communicative competence. Since communication always occurs in a certain occasion, a qualified communicator should use effective communicative strategies with the aim of achieving successful communication.

The experiment illustrated in this thesis proved that integration of cultural teaching into cultivating college learners' communicative competence is a feasible way in modern learning environment.

\section{REFERENCES}

[1] Brown, H. D. (2002). Principles of Language Learning and Teaching. Beijing: Foreign Language Teaching And Research Press.

[2] Deng Yanchang \& Liu Runqing. (1989). Language and Culture. Beijing: Foreign Language Teaching and Research Press.

[3] Dodd, C. H.(2006). Dynamics of Intercultural Communication. Shanghai: Shanghai Foreign Education Press.

[4] Davis, L.(2001). Doing Culture: Cross-cultural Communication in Action. Beijing: Foreign Language Teaching and Research Press.

[5] Gochenour, T., \& Janeway. (1993) Seven Steps in Cross-Cultural Interaction. In Donald Batchelder and Elizabeth G. Warner (Eds), Beyond Experience ( $2^{\text {nd }}$ Ed.). Yarmouth, ME: Intercultural Press.

[6] Hall, J. K. (2005). Teaching and Researching Language and Culture. Beijing: Foreign Language Teaching And Research Press.

[7] Kramsch, C. (2000). Language and Culture. Shanghai: Shanghai Foreign Education Press.

[8] Lado, R. (1957). Linguistics across Culture. Michigan: University of Michigan Press.

[9] Moran, P. R.(2004). Teaching Culture-Perspectives in Practice. Beijing: Foreign Language Teaching And Research Press.

[10] Tao Jiawei. (1998). Writing and Culture. Shanghai: Shanghai Foreign Language Education Press. 


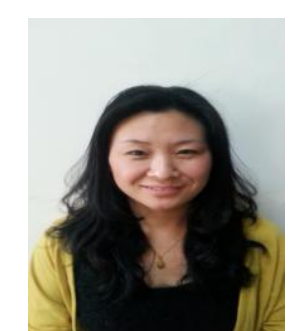

Qian Li was born in Baoding, Hebei province. The author graduated from Chongqing University in Chongqing, China in 2001 and gained the Bachelor's degree of Arts, majoring in English. In 2008, the author gained the Master's degree of Arts in Shandong Normal University.

She has been an English teacher from July of 2001 till now in Shandong Jiaotong University. In October of 2006, she gained the qualification of being a lecturer. During these years from 2001 to 2013 she has taken the foreign language teaching seminars organized by the foreign language teaching and research press for six times in the summer holidays. She has published 21 articles concerning foreign language teaching and researching in recents years. Some of the articles published are as the following: Oversears English, (Hefei, China, Anhui Science \& Technology Publishing House, 2010); Journal of Changchun University of Science and Technology, (Changchun, China, Editorial Board of Journal of Changchun University of Science and Technology, 2011); Time Education (Chengdu, China, Publishing Press of Time Education, 2010). Cross-cultural communication, teaching methods and the study of English as a foreign language are the current research interests of the author.

Ms. Li was the associate editor of Foreign Language Research and Practice which is published by Jilin University publishing press and was awarded "The Best Ten English Teachers of Shandong Province" in 2006. 